\title{
Recording Reference Service
}

$\mathrm{T}$

HE PROBLEM of evaluating reference work has been one of the constantly recurring subjects in our professional literature. It has plagued administrators and reference librarians of college, university, and public libraries. In view of the complexities introduced by such intangibles as the skill of the reference assistant and the importance of the requested information to the inquirer, it is not surprising that a frequent conclusion to their consideration has been despair at ever reaching a satisfactory solution. Nor should it be discouraging. Few of the most valuable possessions or most important intellectual and cultural achievements can be weighed on a scale, measured in inches, or price-marked in dollars and cents to represent their true significance.

Elizabeth Stone in 1942 presented a useful survey of recent "Methods of Evaluating Reference Service," ${ }^{1}$ and Mary N. Barton discusssed stimulatingly the problem in the section on statistics in her paper on "Administrative Problems in Reference Work" at the library institute at the University of Chicago. ${ }^{2}$ It was considered again most recently by Dorothy $\mathrm{E}$. Cole in her "Some Characteristics of Reference Work." 3 But the impossibility of an objective measurement is implicit in the terms that have been used: evaluate, interpret, judge. All of these suggest some use of subjective reasoning and thus there is at the start an irreconcilable conflict in terms. In

1 Library Journal 67:296.98, Apr. 1, 1942.

2 The Reference Function of the Library. University of Chicago Press [cr943], p. 218.48. 1946. this paper the word "evaluate" is discarded entirely, and far from offering a solution to the problem of measuring reference service, the methods currently used by the Reference Department of the Grosvenor Library to "record" services to readers are merely described. There is no illusion that it is a perfect system; some features have been introduced within the past two years and are of course still subject to further study and change. But it has provided useful information and may be suggestive to other libraries.

Three records of reference service are kept at the Grosvenor Library: requests for information by telephone, readers served in person, and unanswered requests whether received by telephone, in person, or by mail. (A fourth record, of books used from the reference collection, is also made by a simple classified tally of the number of books shelved. Since this does not involve any direct service to the reader on the part of a reference librarian it needs no discussion here. All reference librarians will realize that such a tally is far from complete; probably two out of three reference books are returned to the shelves by the reader and no tally is possible. However, the proportionate accuracy from year to year will vary little and the record is thus a valid basis for making a comparison of the amount of use of the reference collection by readers.)

\section{Telephone Service}

The Grosvenor Library publicizes its telephone reference service and encourages the use of this service for questions of fact. 
School assignments are refused, and inquirers are urged to come to the library if their questions require lengthy explanations or involve the interpretation of the information or data supplied. The telephone information desk, supplied with the customary small collection of quick reference tools, is located at the public catalog and the librarian on telephone duty also assists readers at the catalog.

All telephone calls are recorded on a form which provides in addition to the date and the number of the question, spaces for a brief statement of the information wanted, answer and its source, the number of books used to locate the answer, and the initials of the librarian who handled the call. The record sheets are examined daily by the head of the reference department to note trends in public interest, to check staff efficiency, and to discover lacks in the telephone information, reference, or general book collections. It is also useful at the telephone desk itself, since questions frequently are repeated within two or three days.

The number of questions and the number of books used are totaled daily, and the year's total appears in the statistical section of the annual report of the librarian. While one cannot "evaluate" reference service from this quantitative record, it is nevertheless of some significance to be able to point out a 295 per cent increase in telephone requests in the past five years, with the current year showing again a considerable increase over last. And it is a satisfaction to see in the past two years a decrease in the number of books used from 3.27 to 2.57 per question asked.

This telephone reference record has been kept for many years in almost unchanged form, and the record sheets from 1924-30 and 1935 to date have recently been presented to the library of the School of Li- brary Service of Columbia University where they are preserved as source material for library history not only of use to teachers of courses in reference work but also as a body of data suitable for investigation by students in the graduate program.

\section{Persons and Their Requests}

The second record is a tabulation of services rendered in terms of persons served and according to the nature of their requests. This record is kept at all service desks including the telephone information desk where the librarian assists readers in using the public catalogs and handles any questions which come direct to that desk and can be answered from the small book collection there. (Questions by telephone are not tallied on this record.) All questions are tallied as one of the six types of service defined below:

1. Readers Directed: directions to another part of the building, to a specific section of the reference collection, etc.,-purely "location" questions.

2. Readers Instructed : instruction or assistance in the use of tools such as the card catalogs, periodical indexes, bibliographies, etc., or in filling out call slips, procedures in securing books, etc.

3. Readers Advised: advice on the choice of books from the catalogs, probable sources of desired information in the reference collection, etc., where the librarian does not actually go to the books and locate the information.

4. Reference Questions: requests answered by the librarian alone or with the reader from materials in the reference collection.

5. Search Questions: requests answered by the librarian (or readers assisted in answering their own questions) only after consultation of indexes, periodicals, books from the general collection, or extended search in any part of the library.

6. Government Documents: readers helped in the location, identification, or use of U.S. government documents-any type of service involving the reader-staff-documents relationship. 
This sixth type of service needs some clarification. The Grosvenor Library is a depository library for U.S. government documents, which are arranged in a separate stack according to the Superintendent of Documents classification. Except for documents selected for the reference collection they are uncataloged as well as unclassified, although cards are added to the catalogs for documents of exceptional importance and interest (Gen. Marshall's report, or the Bush report, Science: the Endless Frontier, for instance), for valuable documents which the reader might not associate with the usual fields of government publishing, and frequently for bibliographies. The printed indexes and catalogs for documents provide the means of locating and identifying them. The Checklist . . . 1789-1909, Poore, Ames, and the Document Catalogues are in the reference room, as well as most of the departmental indexes, classified in the appropriate subject sections. The file of the Monthly Catalog is kept near the public card catalogs and the telephone information desk. It is, therefore, a rare exception for a reader to avail himself of documents without the help or instruction of a librarian. But for the form of the material involved, tallies in this class would usually fall into Type 2 or 5 above.

\section{Classification}

Miss Stone has pointed out that "one of the greatest difficulties in recording reference questions is inability to classify them and lack of time in which to enter them." The placing of all services in one of these six classes, though they are neither entirely original nor wholly satisfactory, can usually be justified logically. The chief conflict is between Classes 2 (readers instructed) and 3 (readers advised). Many questions,

- Loc. cit. however, are admittedly not entered at all because of pressure of work, and when a number of inquirers follow immediately one upon the other some are forgotten by the time there is an opportunity to get back to the desk. (The reference department is understaffed and one of the reasons for instituting this record was a desire to analyze the types of service requested to see if any of them could be handled in some other way.) It is the consensus of the members of the department that the over-all record is about 60 per cent complete, probably less than this in Types $I$ and 2 which require only brief answers and are therefore quickly forgotten.

For the first full year in which this record was maintained, the ratio of requests for the six types of service is shown in the following table.

Percentage Distribution of Readers Served by Reference Department According to Type of Service
I. Readers Directed 20.6
2. Readers Instructed 26.1
3. Readers Advised
4. Reference Questions
5. Search Questions
14.4
6. Government Documents

This record again, although it is of no help in "evaluating" reference services, has nevertheless revealed interesting facts and suggested certain ways by which it is hoped that the reader may be aided in helping himself. First, the comparatively small number of requests for government documents suggested that by treating them as a special collection, not appearing in the card catalogs, too many people were unaware of the wealth of information lodged there. Since a few documents are cataloged, it is not improbable that some readers have assumed that all could be located through the catalogs and have therefore not asked about a document collection. To bring this to the 
attention of the reader, colored reference cards have been filed into the author catalog under the names of the principal publishing agencies and under important subject headings in the subject catalog. The author card reads:

Additional publications of U.S. government departments, bureaus, agencies, etc., are available in a special collection of government documents.

Please consult a librarian.

The headings used for subject cards, which are similarly phrased, are based on the general headings used for the Price Lists.

\section{Directions about Building}

The number of readers who needed directions after they entered the library seemed to indicate that at least a part of this burden could be lifted from the reference department by a careful study of existing printed signs and directions and thoughtful consideration of possible new signs. The staff had no naive illusion that visitors to the Grosvenor Library could be made to read signs any more than those to any other library. But with the knowledge that even in a small building one out of five requests for help was for simple location directions and that any such requests which could be obviated would mean correspondingly fewer interruptions to a staff hard pressed to meet genuine reference needs, a tour of the building indicated, for instance, that nowhere near the main entrance, the distribution desk, the card catalogs, or the reading room was there a sign directing to the special subject departments (music, medicine, genealogy, and regional history.) Although the reading room was well identified, nothing would indicate to a first visitor that this is also the reference room and the proper place to seek reference assistance. This attempt to make a tour with a layman's untutored mind showed, too, that some of the existing signs were properly worded but improperly placed; they could easily be overlooked.

One out of every four requests was for some sort of instruction. Discussions in staff meetings revealed a preponderant weight of opinion that, while many asked for help in using or interpreting printed reference tools, a disproportionate number of readers needed instruction in the use of the card catalogs and the means of procuring books once they had been located in the catalogs. This seemed to be verified by comparing the figures from each of the service desks and finding that 69.8 per cent of the "readers instructed" were tallied at the desk in the catalog corridor. (Such an impression could be tested more objectively by a short period of noting in every instance the exact nature of instruction given.)

\section{Using the Catalog}

It is without avail to argue with catalogers who insist that the layman cannot and should not be expected to use a catalog. This attitude is nonetheless an admission of failure of the catalog to fulfil one of its primary functions and an insufficient reason for not trying any possible method of helping the reader to help himself. Some readers really prefer to find their own way! To be sure, no instruction is so effective as personal attention at the moment a difficulty is encountered, and when the millennium comes all libraries will have sufficient personnel to carry this out. Until then, it is necessary to try to devise ways to minimize those old questions so familiar to reference librarians-"What is the book number?" "Is this the author?" "How do I fill in this call slip?" "What shall I do with it now?" and "Haven't you something new? This was published in 1889." (Answer: "No, madam; the author was born in 1889 ; the book was published in I942.") 
Borrowing a leaf from the many library handbooks which reproduce a catalog card with its various features explained in the margin, a photostatic enlargement of an actual subject card from the catalog has been made, mounted on a poster allowing plenty of room to call attention to such features as the subject heading, author's name and dates, publication date, pagination, illustrations, bibliographical note, book number, etc., and posted near the catalog. A new call slip form has been printed to provide a better proportioned block for the book number, specific places for volume and date of periodicals, and terse directions for presenting the slips at the distribution desk where books will be delivered. The signs identifying and explaining the contents of the author and subject catalogs have been reworded and relocated.

\section{Unanswered Requests}

The third record regularly kept by the reference department is of unanswered requests, however received, and has been recently introduced. On a simple form are entered the date, name, address, and telephone number of the inquirer, a full and explicit statement of the information wanted, the sources consulted. The librarian who handles the request signs his name, as does the department head or other librarian who checks the search procedure before the inquirer is told the information cannot be found. If the inquirer is referred to another library or agency in the city or elsewhere, this is also noted. Like any record of unanswered requests, this record has administrative value as an indicator, not only of the staff's knowledge of the reference and general collections and their reference technique, but of lacks in the book collection as well. Since a separate sheet is used for each question and a full list of sources consulted is recorded, a single question can be given to a second librarian to work on as time permits if it seems possible that his special subject knowledge or individual differences in approach may enable him to locate the information.

\section{Value of Records}

Though it was pointed out at the beginning that the problem of recording reference service scarcely needs to be called to the attention of librarians, this article has been prepared because it is useful to know of as many systems as possible. It has tried to show also that although the Grosvenor Library has no formula for "evaluating" reference services, by keeping simple records we have to some extent conquered the diffculty of lack of time in which to enter our work. Though a record classified by subject would be useful and a complete record of every question would tell us much about our readers and their interests and about the staff and book collections, the time required not only to write up such reports but even more to analyze and interpret them rules them out when the reference staff is small. Yet an almost purely quantitative record is not to be entirely deprecated; such records have been interesting and revelatory and have pointed the way both to better service and to a reduction of routine demand upon the staff members of the reference department. 